\title{
Thermal Analysis of Electric Machines for Combined Stirling Engine-Generator Performance
}

\author{
V. Zogbochi ${ }^{1}$, P. Chetangny ${ }^{2}$, D. Chamagne ${ }^{3}$, S. Houndedako ${ }^{4}$, G. Barbier ${ }^{5}$, \\ A. Vianou ${ }^{6}$ \\ 1,2,4,6 Department of Electrical Engineering, University of Abomey-Calavi, Abomey-Calavi, Benin \\ ${ }^{3}$ Department of Energy, FEMTO-ST - UMR CNRS 6174, University of Bourgogne Franche-Comte, Belfort, \\ France \\ ${ }^{4}$ Department of Physics and Textile Mechanic, University of Haute Alsace, Mulhouse, France
}

Corresponding Author: V. Zogbochi

\begin{abstract}
The performance of an electric machine depends on its ability to resist rising internal temperature and ambient temperature. In particular when it is a combination with a heat engine, it is essential to know the thermal characteristics of the electric machine in connection with its operating environment to decide which type of machine for a better result. This work will make a comparative thermal study of three types of generators namely: the permanent magnet generator (PMSG), the squirrel cage asynchronous generator (SCIG) and the switched reluctance generator (SRG), all driven by Stirling engine. The method involves solving the heat propagation equation to determine the thermal resistance network for each machine. The resolution of the network combined with the finite element method will allow a comparison of the temperature rise and its effect on the performance of each machine.

The simulation results show that the temperature of the PMSG windings stabilizes at $430 \mathrm{~K}$ while that of the others stabilizes at $373 \mathrm{~K}$ and $346 \mathrm{~K}$ respectively. However, when comparing the performances for the specifications of this work (i.e., produce minimum electric power of $2 \mathrm{~kW}$ at low speed generated by the Stirling engine), PMSG is the one that fulfil all the requirements. For the use of this machine for the generator set, it will be necessary to use magnets of types GNS-39EH whose operating temperature is approximately $473 \mathrm{~K}\left(200{ }^{\circ} \mathrm{C}\right)$ with magnetic induction of $1.22 \mathrm{~T}$.
\end{abstract}

Keywords: choice of machines, thermal network, Finite Element Method, machine's performances, Stirling engine

\section{INTRODUCTION}

Temperature has always been the main factor limiting the performance of an electric machine. This constraint becomes more severe when the machine is required to be used in applications where the ambient temperature is very high. It is often the case in confined spaces like under the hood of a car, starter generator for thermal engines, etc. Indeed, the insulation of the winding of electric machines being composed of polymers, they degrade under the effect of high temperatures which results in irreversible damage to the machine and limit its life ${ }^{[1]}$. Many research works have been carried out to understand the thermal behavior of electric machines. The methods developed are classified into three categories ${ }^{[2]}$ : Equivalent Thermal Circuits (ETC) ${ }^{[3]}$, Finite Elements Methods (FEM) ${ }^{[4]}$ and Computer Fluid Dynamic (CFD) ${ }^{[5]}$ ${ }^{[6]}$. C. Espanet et al ${ }^{[7]}$ compared the method of the ETC and FEM for permanent magnet machines. The results of this work show that the two methods can be adapted for permanent magnet machines except for losses in magnets. CFD and ETC are also compared in [8] and arrived at the concordance of both models with experimental results. Adouni A. et al ${ }^{[9]}$ in their work on thermal analysis of 
Synchronous Reluctance Machine (SRM) make a comparison between ETC, FEM and CFD. The conclusion from this work say that FEM approach should be adopted when the study is for design purposes and when the study is just for fluid flow behavior in the machine, CFD is compulsory. However, when the instantaneous temperature value constitutes the most important requisite, ETC is the more appropriate method. In ${ }^{[10]}$, authors made thermal study of different electric machine namely DC machine, induction machine, servo motors and permanent magnet DC machine. In order to determine the effect of temperature rise in the machines, this work make use of analytical formulas and end up by saying that temperature is a major factor which affect the machines performances. To bring out the behavior of electric machines when located in confined area, author in [11] conducted a thermal study for automobile alternator. Aero-thermal model is employed to determine the temperature rise in claw machine and end up with the best cooling system for the alternator. As combination of electric machine and thermal one faces the challenge of confinement and cooling, authors try to analyse the best practice that can increase the feasibility of the concept. In this perspective, S. Alfarawi et al [12] develop a thermal model of Stirling engine and automotive alternator that is powered by exhaust gas. CFD is used to study heat transfer in the block formed by Stirling engine and alternator. The results showed that it is possible to generate electric power of $1.5-2 \mathrm{kWe}$ at an ideal thermal efficiency of $40 \%$ and engine overall weight of $80-$ $120 \mathrm{~kg}$.

The purpose of this work is to analyse the performances of different electric machines combined with Stirling engine for power generation. Stirling engine is an external combustion machine that contains hot head and cold head. Heat is generated at the hot head and creates mechanical output according to the Stirling cycle. This machine will be used to drive an electric generator which will be located in its cold part and form a light generator which can be moved by hand and adapted to several renewable sources. Emphasis was made on the fact that the electric machine will work in a confined environment and that the heat can come from the outside air.

\section{THERMAL ANALYSIS OF THE ELECTRIC MACHINES}

\section{- Heat sources in electric machines}

Temperature rise inside the machine is caused by heat generated from different loss mechanisms: Joule loss, iron loss, mechanical loss and stray losses. Figure 1 shows different types of losses and the link between them.

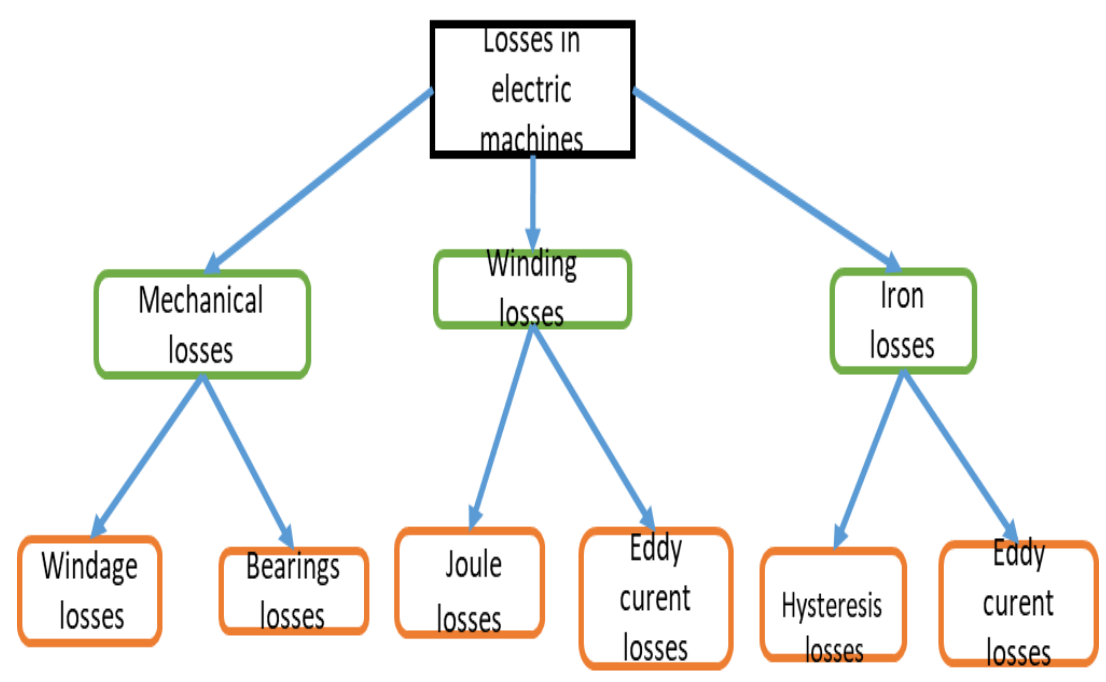

Fig.1: Heat sources in electric machines 
- Power losses calculation in electric machines

- Joule losses

Also known as copper loss or Ohmic loss, Joule loss is the power dissipated in stator and rotor windings due to the resistance of copper wire

$$
P_{c u}=m I_{r m s}^{2} R
$$

Where $\mathrm{m}$ is the number of phases, $\mathrm{I}_{\mathrm{rms}}$ is the root mean square of phase current and $\mathrm{R}$ is the Alternative Current armature resistance of the phase winding.

$$
R=k_{r} \frac{N l_{a v}}{\sigma S_{c}}
$$

Where $\mathrm{k}_{\mathrm{r}}$ is the skin effect factor, $\mathrm{N}$ the number of turns, $l_{\mathrm{av}}$ the average length of a turn, $S_{c}$ the cross-sectional area of the conductor and $\sigma$ the specific conductivity of the conductor.

\section{- Core loses}

Core loses are caused by alternating flux in the iron core which to resist changes in the flux. As a result, there is a differential power loss being modeled by Steinmetz ${ }^{[13]}$

$$
P_{\text {core }}=K_{h} B^{2} f+K_{c}(B f)^{2}+K_{e}(B f)^{3 / 2}
$$

Where $K_{h}, K_{c}$, and $K_{e}$ are the coefficients of hysteresis loss, classical eddy current loss, and excess eddy current loss, respectively, and $\mathrm{B}$ is the peak flux density.

\section{- Mechanical losses}

Mechanical losses are a consequence of bearing friction and windage. Bearing losses depend on the shaft speed, bearing type, properties of the lubricant and the load on the bearing. Bearing losses are modeled as ${ }^{[14]}$

$$
P_{\text {bearing }}=\frac{1}{2} \Omega \xi F D_{b}
$$

Where $\Omega$ is the angular frequency of the shaft supported by a bearing, $\xi$ the friction coefficient (typically 0.0010-0050), F the bearing load and $\mathrm{D}_{\mathrm{b}}$ the inner diameter of the bearing

Windage losses are a consequence of the friction between the rotating surfaces and the surrounding gas, usually air. It is defined as:

$$
P_{\text {win }}=\frac{1}{32} k C_{M} \pi \rho \Omega^{3} D_{r}^{4} L_{r}
$$

Where $\mathrm{k}$ is a roughness coefficient (for a smooth surface $\mathrm{k}=1$, usually $\mathrm{k}=1-1.4$ ), $\mathrm{C}_{\mathrm{M}}$ the torque coefficient, $\rho$ the density of the coolant, $\Omega$ the angular velocity, $\mathrm{D}_{\mathrm{r}}$ the rotor diameter and $\mathrm{L}_{\mathrm{r}}$ the rotor length. The torque coefficient is obtained as follows:

$C_{M}=10 \frac{2\left(\frac{\varepsilon}{D_{r}}\right)^{0.3}}{R_{e \delta}}, R_{e \delta} \prec 64$

Where $R_{e \delta}=\frac{\rho \Omega D_{r} \varepsilon}{2 v}$ is called Couette Reynolds number, $\varepsilon$ is the air-gap length and $v$ is the dynamic viscosity of the coolant.

Other losses such as ventilation losses and end surface losses also count for mechanic but are neglected for the scope of this work.

The mechanical losses $\left(\mathrm{P}_{\text {mech }}\right)$ is:

$P_{\text {mech }}=P_{\text {win }}+P_{\text {bearing }}$

And total power losses

$P_{\text {loss }}=P_{\text {core }}+P_{c u}+P_{\text {mech }}$

The process of power flow in the machine is depicted in figure 2 showing how the input mechanical energy is been transformed into electric power. This led to the definition of the machine's efficiency as follow:

$$
\eta=\frac{P_{\text {out }}}{P_{\text {out }}+P_{\text {losses }}}
$$

The above equations for losses calculation are valid for the types of machines we use in this work. 


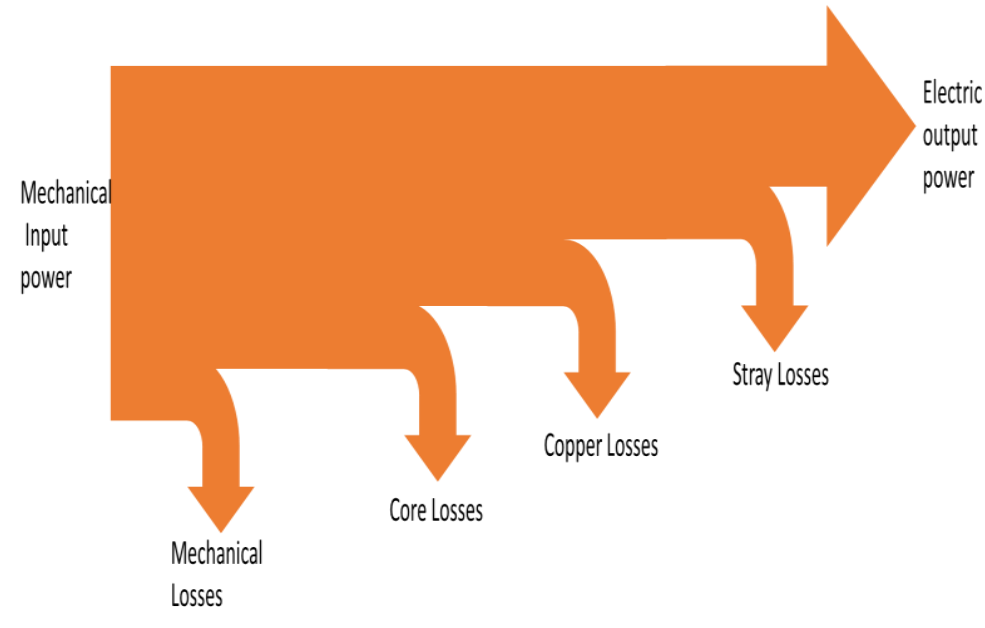

Fig.2: Power flow diagram of electric generator

\section{- Heat maps comparison}

In order to analyze the specificity of these equations in accordance with each machine, we have input the machines characteristic in JMAG software ${ }^{[15]}$ to visualize the total losses maps. The results are shown in fig.3. Each generator running at $1000 \mathrm{rpm}$, we notice that maximum losses in permanent magnet machine occurs in constant torque region and can reach $120 \mathrm{~W}$ while SRG and Induction machine reaches maximum of $70 \mathrm{~W}$ and $100 \mathrm{~W}$ respectively in constant power region. More power losses are generated in PM machine at starting because of the presence of remanence magnetic force that must be overcome.

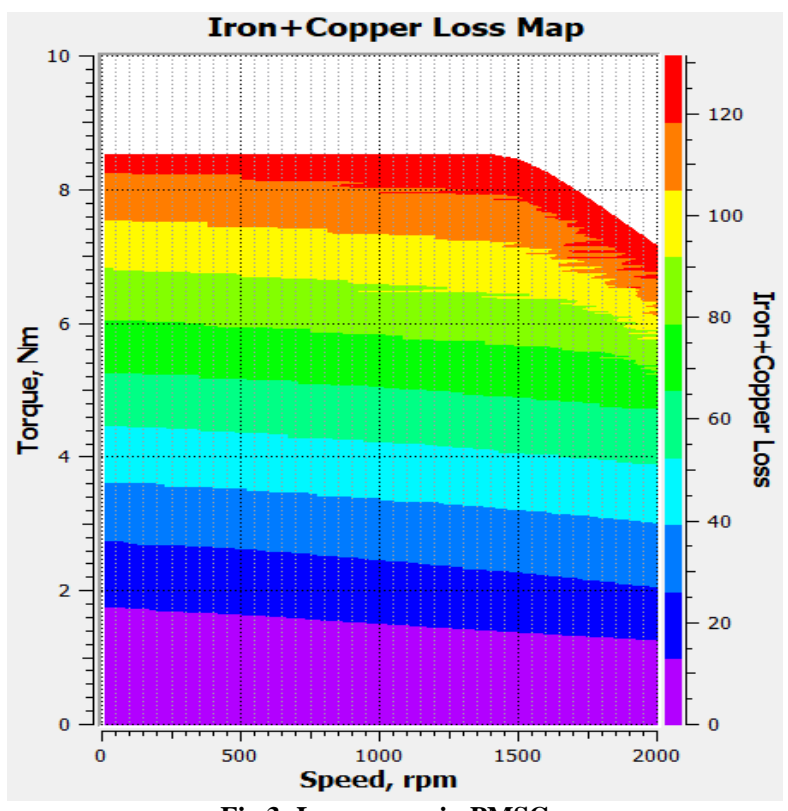

Fig.3: Losses map in PMSG

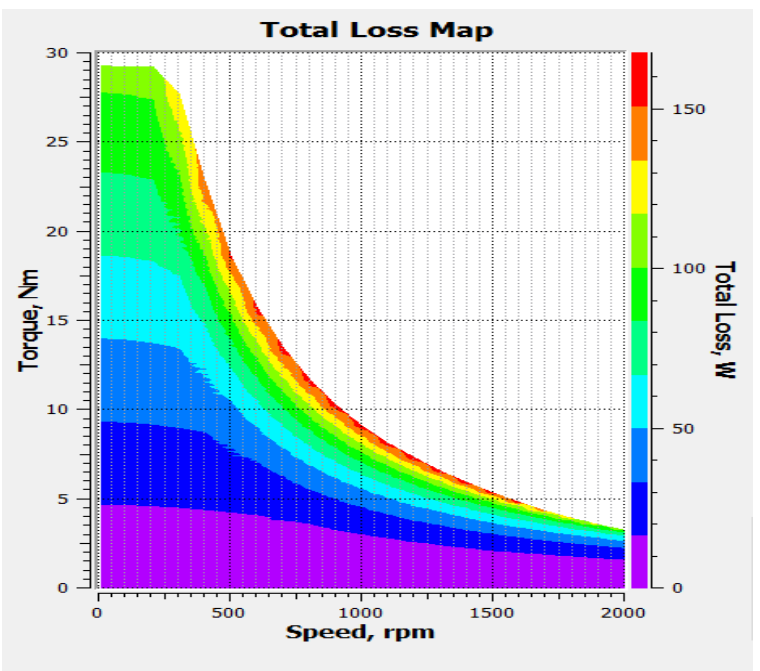

Fig.4: Losses map in SCIG

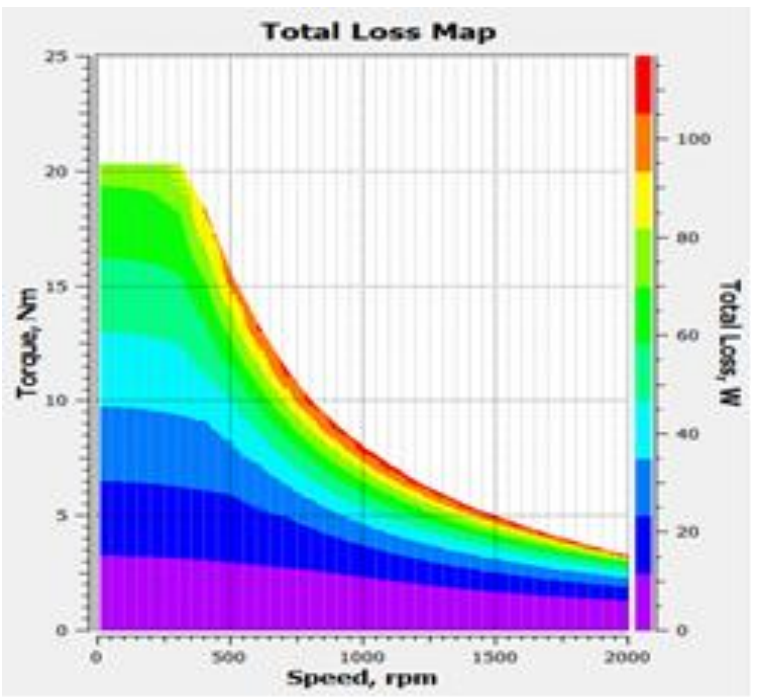

Fig.5: Losses map for SRG

- Heat propagation equation solving

The electromechanical energy conversion in electric machine is always 
accompanied with electromagnetic and mechanical losses. The losses cause the temperature raise in machine which is transfer from the active parts of the machine to the environment. Assume the heat generated per unit volume per second is $\mathrm{Qv}$ watts per cubic centimeter, the heatconduction equation is:

$$
\frac{\partial T}{\partial t}=h^{2} \nabla^{2} T+\frac{Q_{v}}{\rho C_{p}}
$$

Where $h=\frac{\lambda}{\rho C_{p}}$ is thermal diffusibility, $\lambda=$ thermal $\quad$ conductivity, $\quad \rho=$ density, $C_{p}=$ specific heat and $T=$ temperature.

At steady state, $\frac{\partial T}{\partial t}=0$ and equation (10) becomes Poisson equation

$$
\nabla^{2} T+\frac{Q_{v}}{h^{2} \rho C_{p}}=0
$$

The initial temperature rise is directly proportional to the energy generated at a point. This energy is the sum of different power losses (Joule losses, mechanical losses, iron losses and eddy losses) calculated above using electromagnetic model and represented as $Q_{v}[16],[17]$ becomes:

In radial direction, this equation

$$
\frac{d^{2} T}{d r^{2}}+\frac{1}{r} \frac{d T}{d r}+\frac{Q_{v}}{K_{r}}=0\left(0 \leq \mathrm{r} \leq \mathrm{R}_{s}\right)
$$

$K_{r}$ is the thermal conductivity in radial direction. Also, heat equation in axial direction is written as:

$$
\frac{d^{2} T}{d z^{2}}+\frac{Q_{v}}{K_{a}}=0(0 \leq \mathrm{z} \leq \mathrm{L})
$$

$K_{a}$ is the thermal conductivity in axial direction and $\mathrm{L}$ is the length of the machine. Solution to equations (12) is given as follow:

$$
T_{r}(r)=-\frac{Q_{v} r^{2}}{4 K_{r}}+a \ln (r)+b
$$

$\mathrm{a}$ and $\mathrm{b}$ are constants depending on boundary conditions. In this case, these conditions correspond to the temperature limits at the initial operation defined at the inner radius and outer radius of the machines.

$$
\begin{aligned}
& a=\frac{1}{\ln \left(\frac{r_{2}}{r_{1}}\right)}\left[T_{2}-T_{1}+\frac{Q_{v}\left(r_{2}^{2}-r_{1}^{2}\right)}{4 K_{r}}\right] \quad(14) \\
& b=\frac{1}{\ln \left(\frac{r_{2}}{r_{1}}\right)}\left[T_{1} \ln \left(r_{2}\right)-T_{2} \ln \left(r_{1}\right)+\frac{Q_{v}\left(r_{1}^{2} \ln \left(r_{2}\right)-r_{2}^{2} \ln \left(r_{1}\right)\right)}{4 K_{r}}\right]
\end{aligned}
$$

The average temperature is written as:

$$
\begin{aligned}
T_{r_{-} \text {arg }} & =\frac{Q_{v}}{8 K_{r}}\left[\left(r_{2}^{2}-r_{1}^{2}\right)-\frac{\left(r_{2}^{2}-r_{1}^{2}\right)}{\ln \left(\frac{r_{2}}{r_{1}}\right)}\right]+T_{1}\left[\frac{1}{2 \ln \left(\frac{r_{2}}{r_{1}}\right)}+\frac{r_{1}^{2}}{\left(r_{2}^{2}+r_{1}^{2}\right)}\right]+T_{2}\left[\frac{r_{2}^{2}}{\left(r_{2}^{2}-r_{1}^{2}\right)}-\frac{1}{2 \ln \left(\frac{r_{2}}{r_{1}}\right)}\right] \\
& =p\left(R_{r 3}+\frac{R_{r 2} R_{r 1}}{R_{r 2}+R_{r 1}}\right)+T_{1} \frac{R_{r 2}}{R_{r 2}+R_{r 1}}+T_{2} \frac{R_{r 1}}{R_{r 2}+R_{r 1}}
\end{aligned}
$$

With

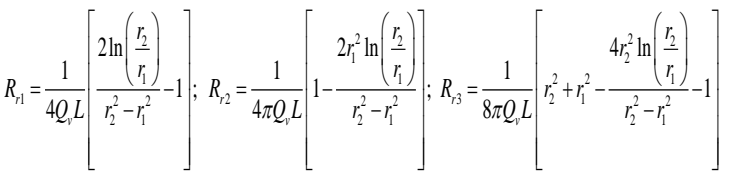

$$
\begin{aligned}
& P=2 \pi\left(r_{2}^{2}-r_{1}^{2}\right) L Q
\end{aligned}
$$

$r_{2}, r_{1}$ and $\mathrm{L}$ are the external radius, internal radius and length of the elementary component of the machine.

In axial direction, the temperature flow is defined by equation (13) and is solved as:

$$
T_{z}(z)=-\frac{Q_{v}}{2 K_{a}}\left(z^{2}-L z\right)+\frac{T_{2}-T_{1}}{L} z+T_{1}
$$

The axial average temperature is:

$$
\begin{aligned}
& T_{z_{-} a v g}=\frac{Q_{v} L^{2}}{12 K_{a}}+\frac{T_{2}+T_{1}}{2}=\frac{P \cdot R_{a}}{12}+\frac{T_{2}+T_{1}}{2} \\
& P=Q_{v} L \text { and } R_{a}=\frac{L}{K_{a}} .
\end{aligned}
$$

To model the transient phenomena, the thermal capacitor is introduced at the heat source to simulate the heat expansion over time.

The bidirectional thermal network of the elementary component of the machine is presented in figure 6 : 


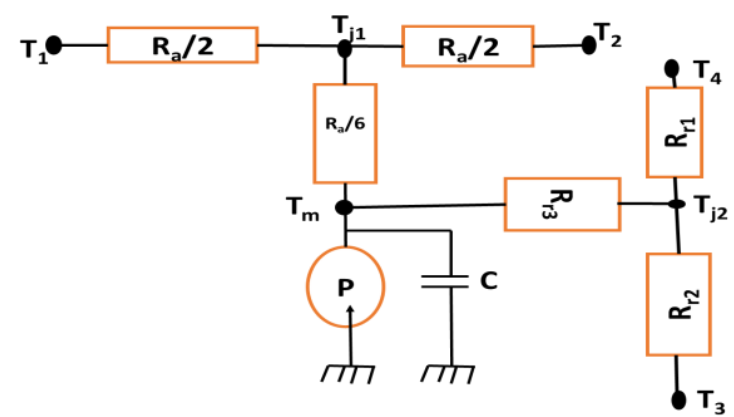

Fig.6: Bidirectional $\mathrm{T}$ shape equivalent thermal network of electric machine, $\mathrm{T} 1, \mathrm{~T} 2$ and $\mathrm{T3}$ are the temperatures at the end surfaces of radial and axial elements, $R a$ is axial thermal resistance, $R r$ is radial thermal resistance ${ }^{[16]}$.

\section{- Heat transfer in the air gap}

The air gap is the rotational flow region where it is difficult to evaluate the heat transfer coefficients. The current approach is mainly estimating these exchange coefficients. In the air gap, the flow and heat transfer are governed by the number of Taylor (Ta) given by:

$T_{a}=\frac{r_{e x} \omega^{2} \varepsilon^{3}}{v^{2}}$

$v$ the kinematic viscosity of the air, $\varepsilon$ the thickness of the air gap $\omega$ is the angular velocity and $r_{e x}$ the outer radius of the rotor. This flow can be model by considering the air gap as a confined space between two coaxial cylinders. The internal cylinder is rotating and in the absence of axial air flow, the exchange coefficient is obtained from the relation introducing the Taylor number. We have ${ }^{[18]}$ :

$\left\{\begin{array}{l}N_{u}=2.2 \text { for } T_{a} \leq 41 \\ N_{u}=0.23 T_{a}^{0.63} P_{r}^{0.27} \text { for } 41 \leq T_{a} \leq 100\end{array}\right.$

Where $T_{a}=\operatorname{Re} \sqrt{\frac{2 \varepsilon}{d}}$ is the Taylor number, $\operatorname{Re}=\frac{\omega d \varepsilon}{2 v}$ is Renault number and $P_{r}=\frac{\mu_{d} C_{p}}{\rho_{\text {air }}}$ is Prandtl number. $\mu_{d}$ is the dynamic viscosity $\rho_{\text {air }}$ is air density and d is rotor external diameter. The critical value 41 of the Taylor number corresponds to the transition from a laminar flow regime to a turbulent regime. Note that for the application of Stirling Engine generator, the machine is operated at low speed so the
Taylor number is always less than 41 and we have $\mathrm{Nu}=2.2$. also, the air gap is reduced to the minimum making the confinement important in radial direction. We can then assume that the heat transfer is essentially provided by conduction. By taking into account the convection in the air gap, the heat exchange coefficient is defined as:

$c_{a g}=\frac{2.2 \rho_{a i r}}{\varepsilon}$

\section{- Thermal equivalent network of the machine}

For the whole machine, the combination of directional and bidirectional network permits us to obtain a complete thermal network. Because of symmetry, we divide the entire machine into four parts in order to simplify the computation time and get more accurate results. An example of PMSG is presented in figure 7. A similar network is realized for induction machine and switched reluctance machine for comparative analysis.

In this figure, friction losses occur in the bearing and Iron losses occurs in in the Stator yoke. Joule losses appear in stator winding through end winding and rotor surface is subjected to losses due to the presence of magnets who generate magnetic force that must be overcome.

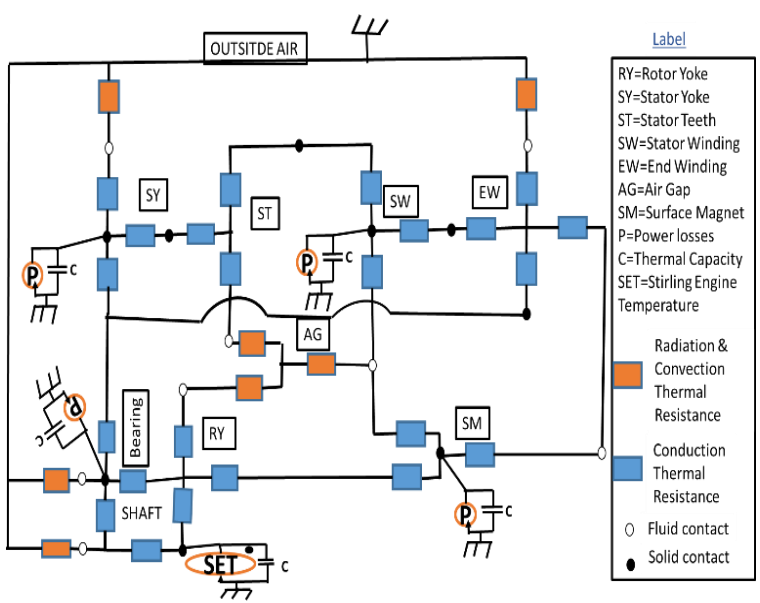

Fig.7 : Simplified thermal network of surface mounted permanent magnet generator

RESULT

\section{- Temperature rise analysis}

An implementation of this network is done in MATLAB Simulink software to 
analyze the temperature rise in machines over time (see figure 6). The different thermal resistances are chosen according to the type of transfer in the specific part of the machine. The simulation results are shown in figure $7 ; 8$ and 9

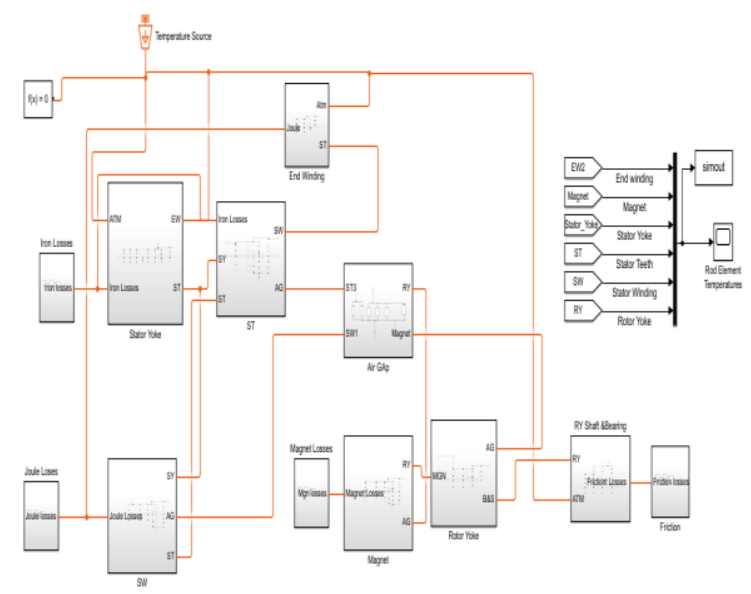

Fig.8: Thermal network implementation in Matlab Simulink

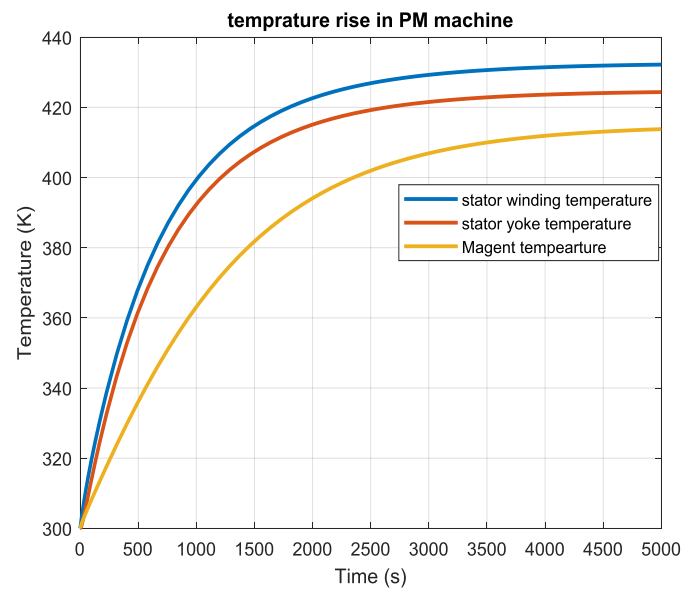

Fig.9: Temperature rise in Permanent magnet machine

Over the first 2000 seconds, the temperature increases quickly from $300 \mathrm{~K}$ $\left(27^{\circ} \mathrm{C}\right)$ to reach the values of $420 \mathrm{~K}$ in the winding before growing smoothly to stabilize at $435 \mathrm{~K}$ after some times.

In order to visualize the temperature rise in steady state, we develop a model of each machine in Motor-CAD software. The results are shown in figure 10,11 and 12 . We observe rapid temperature rise in permanent magnet machine compare to the remaining machine. The temperature stabilizes at $430 \mathrm{~K}$ and $416 \mathrm{~K}$ in the stator winding and rotor surface magnet respectively. Likewise, the induction machine and switched reluctance machine stator winding stabilize at $373 \mathrm{~K}$ and $346 \mathrm{~K}$ respectively. This temperature rise in the magnet may decrease the machine performance or cause demagnetization. However, choosing $\mathrm{NdFeB}$ magnet of type GNS-39EH, the operating temperature is above $473 \mathrm{~K}\left(200^{\circ} \mathrm{C}\right)$ with magnetic remanence of 1.220 Tesla. Thus, permanent magnet generator can withstand the temperature rise and perform well as required.

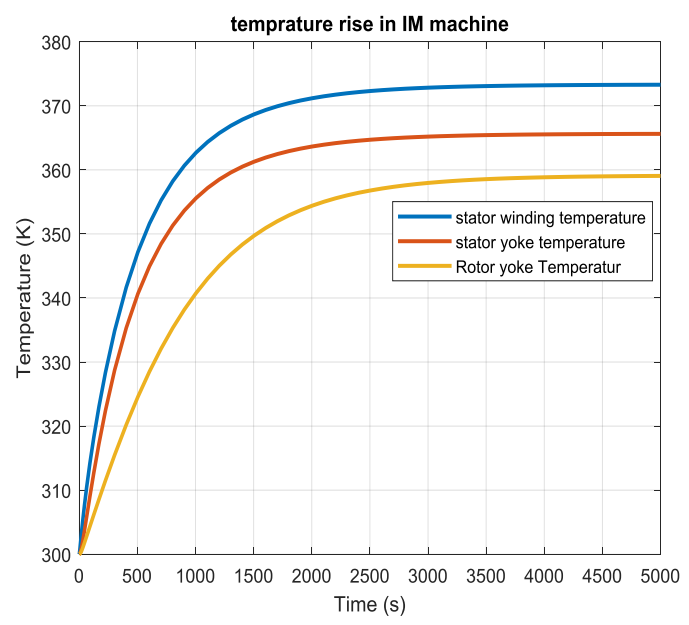

Fig.10: Temperature rise in Induction machine

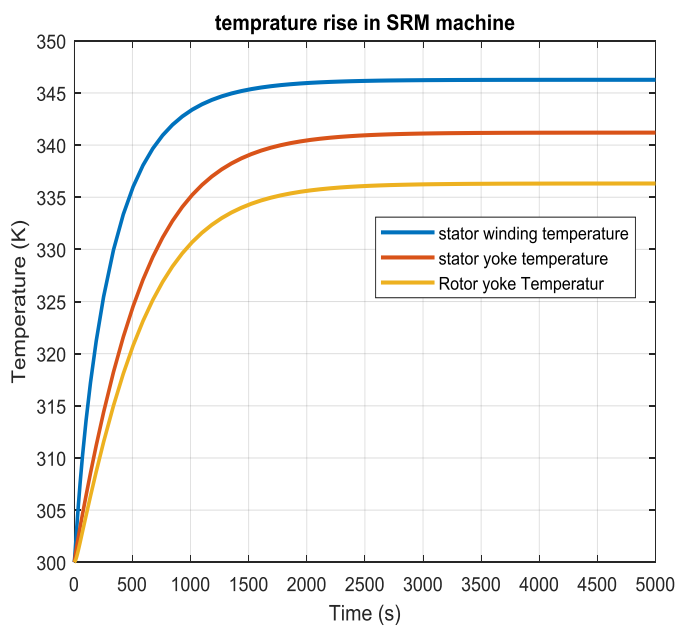

Fig.11: Temperature rise in Switched reluctance machine

\section{- FEM}




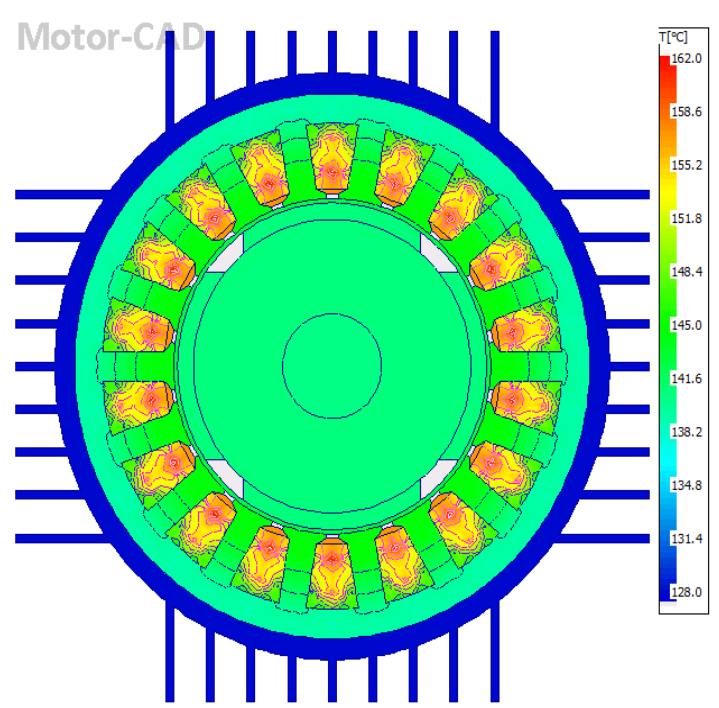

Fig.12: Steady state temperature for Permanent Magnet Synchronous Generator

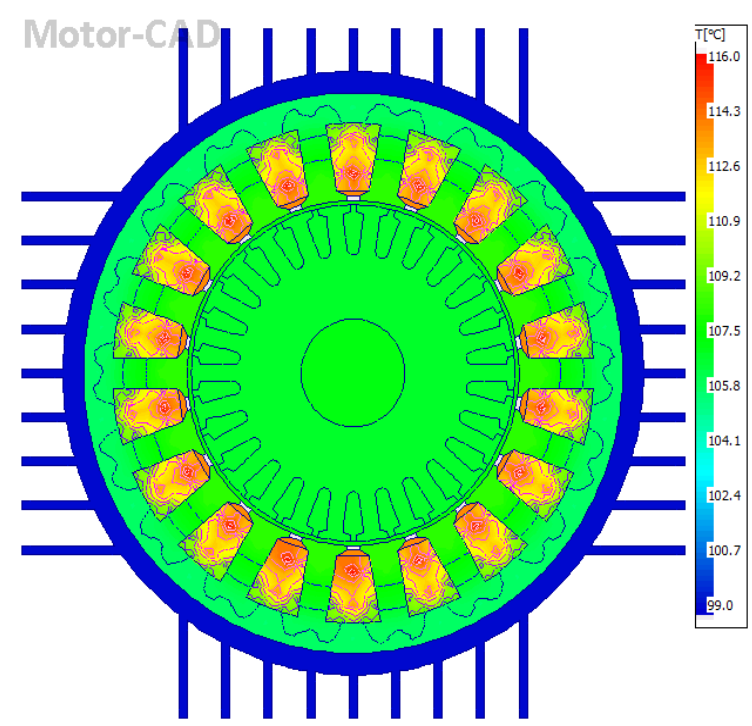

Fig.13: Steady state temperature for induction Generator

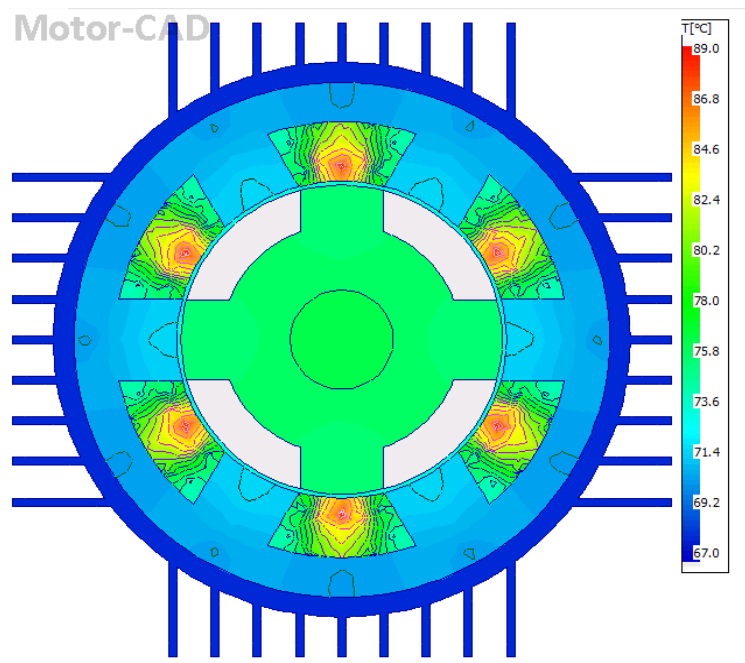

Fig.14: Steady state temperature for Switched Reluctance Generator

- Effect of temperature rise on the machines' performances
We analyze the performance of the electric machine in relation to the temperature rise and tried to simulate the evolution of the machine's efficiency as function of temperature. We fix the running speed at $1500 \mathrm{rpm}$ and other parameters are kept constant. The results are shown in Fig.15 where the efficiency of the machine goes from initial efficiency of $91 \%$ at ambient temperature and completely demagnetize at $265^{\circ} \mathrm{C}$ when using GNS39EH magnet. The red part of the curve shows the interval where there is no output power. In addition, the electrical endurance qualities of insulation materials are affected by temperature rises and reduce their life time. So it become necessary to evacuate the heat generation in the machine and also prevent it from heat radiated from hot head of the Stirling engine

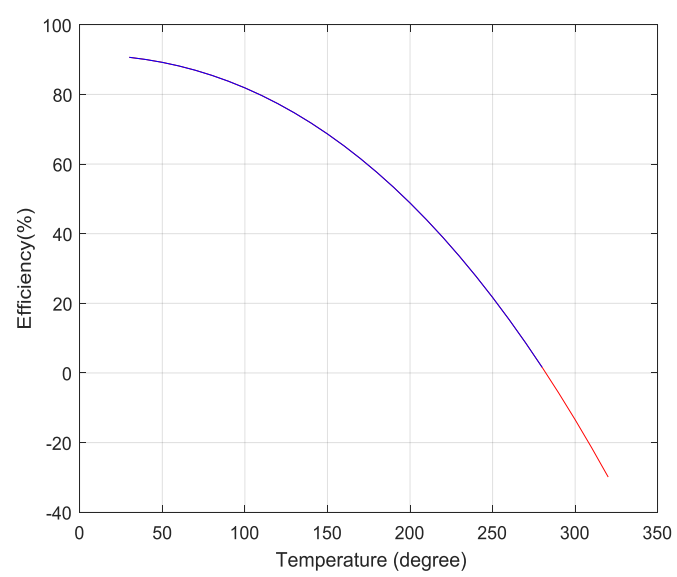

Fig.15: effect of temperature rises on machine efficiency

\section{CONCLUSION}

This work explores analytical model mainly lumped parameter thermal circuit and finite element method to compare the thermal characteristic of three types of generators that can be combined with Stirling engine to make one displaceable compound that could be adapted to many heat sources. The analytical model takes into to account the fact that the machine may be subjected to external temperature rise and the cooling effect due to confinement. The results show that the machine that can withstand these conditions is switched reluctance machine. But for the 
type of application, the machine will be subjected to low-speed operation and may not be able to produce the minimum power required. Permanent magnet generator can perform well in term of power, torque and global efficiency of the block. But it uses may cause precocious demagnetization due to rapid temperature rise. By using $\mathrm{NdFeB}$ magnet of type GNS-39EH which operating temperature is above $473 \mathrm{~K}\left(200^{\circ} \mathrm{C}\right)$ and magnetic remanence of 1.220 Tesla. This type of magnet can guarantee the maximum operating point for PMSG for better performance. However, it is necessary to provide better ventilation system for the electric machine to eliminate the heat generated inside the machine in order to prevent the insulation materials from rapid damage

\section{REFERENCES}

1. E. L. Brancato, «Estimation of lifetime expectancies of motors », IEEE Electr. Insul. Mag., vol. 8, no 3, p. 5-13, mai 1992, doi: 10.1109/57.139066.

2. A. Boglietti, A. Cavagnino, D. Staton, et al «Evolution and Modern Approaches for Thermal Analysis of Electrical Machines », IEEE Trans. Ind. Electron., vol. 56, no 3, p. 871-882, mars 2009, doi: 10.1109/TIE.2008.2011622.

3. G. Kylander, " Thermal modelling of small cage induction motors », $\mathrm{PhD}$ Thesis, Chalmers Univ. of Technology, Göteborg, 1995.

4. A. Abdullah, M. Amer, et A. Ali, « Thermal analysis of a three-phase induction motor based on motor-CAD, flux2D, and matlab », Indones. J. Electr. Eng. Comput. Sci., vol. 15, p. 46-53, juill. 2019, doi: 10.11591/ijeecs.v15.i1.pp4653.

5. M. L. Hosain, R. B. Fdhila, et K. Rönnberg, « Air-gap Flow and Thermal Analysis of Rotating Machines using CFD », Energy Procedia, vol. 105, p. 51535159, mai 2017, doi: 10.1016/j.egypro.2017.03.1045.

6. Y.-C. Chen, B. Chen, C. Chen, et al « CFD Thermal Analysis and Optimization of Motor Cooling Fin Design », janv. 2005, doi: 10.1115/HT2005-72567.

7. C. Espanet, A. Cassat, et N. Wavre, « Comparaison des analyses thermiques d'un moteur-couple à aimants permanents par méthode nodale et par éléments finis tridimensionnels », nov. 2001.

8. Z. Kolondzovski, P. Sallinen, et A. Arkkio, "Thermal analysis of a highspeed PM machine using numerical and thermal-network method », in The XIX International Conference on Electrical Machines - ICEM 2010, sept. 2010, p. 16 , 10.1109/ICELMACH.2010.5607731.

9. A. Adouni et A. J. M. Cardoso, « Thermal Analysis of Synchronous Reluctance Machines - A Review », Electr. Power Compon. Syst., vol. 47, no 6-7, p. 471485, avr. 2019, doi: 10.1080/15325008.2019.1602688.

10. S. M. N. Ali, A. Hanif, Q. Ahmed, « Review in thermal effects on the performance of electric motors », in 2016 International Conference on Intelligent Systems Engineering (ICISE), janv. 2016, p. 83-88, doi: 10.1109/INTELSE.2016.7475166.

11. J. Lutun, "Modélisation thermique des alternateurs automobiles », phdthesis, Université de Grenoble, 2012.

12. S. Alfarawi, M. Webb-Martin, S. Mahmoud, et al «Thermal Analysis of Stirling Engine to Power Automotive Alternator Using Heat from Exhaust Gases », Energy Procedia, vol. 61, p. 2395-2398, déc. 2014, doi: 10.1016/j.egypro.2014.12.013.

13. C. Huynh, L. Zheng, D. Acharya, « Losses in High Speed Permanent Magnet Machines Used in Microturbine Applications », J. Eng. Gas Turbines Power, vol. 131, no 2, mars 2009, doi: 10.1115/1.2982151.

14. P. Juha, J. Tapani, H. Valéria, Design of Rotating Electrical Machines. Chichester, West Sussex, United Kingdom ; Hoboken, NJ: Wiley-Blackwell, 2008.

15. « Simulation Technology for Electromechanical Design: JMAG », Simulation Technology for Electromechanical Design: JMAG. 
https:/www.jmag-international.com/ (consulted on August 10, 2020).

16. G. R. G. Guemo, « Modélisation et caractérisation thermique de machines électriques synchrones à aimants permanents », phd thesis, INSA de Lyon, 2014.

17. S. Mezani, N. Takorabet,, B. Laporte, «A combined electromagnetic and thermal analysis of induction motors », IEEE Trans. Magn., vol. 41, no 5, p. 1572-1575, mai 2005, doi: 10.1109/TMAG.2005.845044.
18. D. Roye, Modélisation thermique des machines électriques tournantes: application à la machine à induction. phd thesis, Grenoble, 1983.

How to cite this article: V. Zogbochi, P. Chetangny, D. Chamagne et.al. Thermal analysis of electric machines for combined stirling engine-generator performance. International Journal of Research and Review. 2021; 8(3): 621-630. 